\title{
Enhanced electric and magnetic response of a THz sub-wavelength fiber excited by a localized source
}

Atakaramians, Shaghik; Stefani, Alessio; Shardivov, llya V.; Miroshinchenko, Andrey E.; Kulhmey, Boris T.; Ebendorff-Heidepriem, Heike; Monro, Tanya M.; Kivshar, Yuri S.; Shahraam Afshar, V.

\section{Published in:}

Proceedings of 2017 Conference on Lasers and Electro-Optics Europe \& European Quantum Electronics

Conference (CLEO/Europe-EQEC)

Link to article, DOI:

10.1109/CLEOE-EQEC.2017.8087102

Publication date:

2017

Document Version

Peer reviewed version

Link back to DTU Orbit

Citation (APA):

Atakaramians, S., Stefani, A., Shardivov, I. V., Miroshinchenko, A. E., Kulhmey, B. T., Ebendorff-Heidepriem, H., Monro, T. M., Kivshar, Y. S., \& Shahraam Afshar, V. (2017). Enhanced electric and magnetic response of a THz sub-wavelength fiber excited by a localized source. In Proceedings of 2017 Conference on Lasers and ElectroOptics Europe \& European Quantum Electronics Conference (CLEO/Europe-EQEC) IEEE.

https://doi.org/10.1109/CLEOE-EQEC.2017.8087102

\section{General rights}

Copyright and moral rights for the publications made accessible in the public portal are retained by the authors and/or other copyright owners and it is a condition of accessing publications that users recognise and abide by the legal requirements associated with these rights.

- Users may download and print one copy of any publication from the public portal for the purpose of private study or research.

- You may not further distribute the material or use it for any profit-making activity or commercial gain

- You may freely distribute the URL identifying the publication in the public portal 


\title{
Enhanced electric and magnetic response of a THz sub-wavelength fiber excited by a localized source
}

\author{
Shaghik Atakaramians ${ }^{1}$, Alessio Stefani ${ }^{1,2}$, Ilya V. Shardivov ${ }^{3}$, Andrey E. Miroshinchenko ${ }^{3}$, Boris T. \\ Kulhmey ${ }^{1}$ Heike Ebendorff-Heidepriem ${ }^{4}$, Tanya M. Monro ${ }^{4,5}$, Yuri S. Kivshar ${ }^{3}$, Shahraam Afshar ${ }^{4,5}$ \\ 1. Institute of Photonics and Optical Science, School of Physics, The University of Sydney, Sydney NSW 2006, Australi \\ 2. DTU Fotonik, Department of Photonics Engineering, Technical University of Denmark, DK-2800 Kgs. Lyngby, Denmark \\ 3. Nonlinear Physics Centre, Research School of Physics and Engineering, Australian National University, Canberra ACT 2601, Australia \\ 4. Institute for Photonics and Advanced Sensing, The University of Adelaide, Adelaide SA 5005, Australia \\ 5. Laser Physics and Photonic Devices Laboratories, School of Engineering, University of South Australia, SA 5095, Australia
}

Recently we have shown that a nanofiber excited by a localized electric source can have enhanced electric and magnetic response depending of the relative orientation of the source and the fiber [1]. We have demonstrated that the dielectric nanofiber can suppress the electric response and enhance the magnetic response of the coupled system when excited with an electric dipole oriented along the circumference of the fiber. This result introduces a new platform for achieving enhanced magnetic response, which is the fundamental building block for metamaterial devices. Here we investigate experimentally the scattering of $\mathrm{THz}$ radiation from a subwavelength fiber excited by a localized source. We observe resonance peaks in the scattered light and attribute them to combined excitation of several lower order Whispering Gallery Modes (WGMs) of the fiber. To the best of our knowledge, this is the first demonstration of sub-wavelength fiber resonances at THz frequencies due to a localized source.

We used a $300 \mu \mathrm{m}$ soft-glass fiber (F2 with $\mathrm{n}=2.7$ and $\alpha<101 / \mathrm{cm}$ [2]) and a 300um circular aperture (subwavelength for $\mathrm{f}<0.5 \mathrm{THz}$ ) in a very thin copper plate to create a localized source. Using a $\mathrm{THz}$ photoconductive near-field probe we measured the electric field over a square area of $850 \times 850 \mu \mathrm{m}^{2}$ parallel to the aperture, for the bare aperture and for aperture-fiber system (fiber in front of the aperture). The normalized integrated powers over the scanned area are shown in Fig. 1(a) for aperture only and aperture-fiber. The results closely match the numerical results obtained from CST Microwave Studio (dashed lines). As expected for a bare aperture the maximum transmission is observed when the diameter is equal to half of the operating wavelength $(\lambda=600 \mathrm{~nm})$. When the fiber is placed in front of the aperture, enhanced transmission is observed around $0.3 \mathrm{THz}$ due to electric and/or magnetic resonances of the fiber. The electric field intensity at $0.3 \mathrm{THz}$ of the bare aperture (Fig.1(b)) and the aperture-fiber system (Fig. 1(c)) also verifies the enhanced transmission through the system.

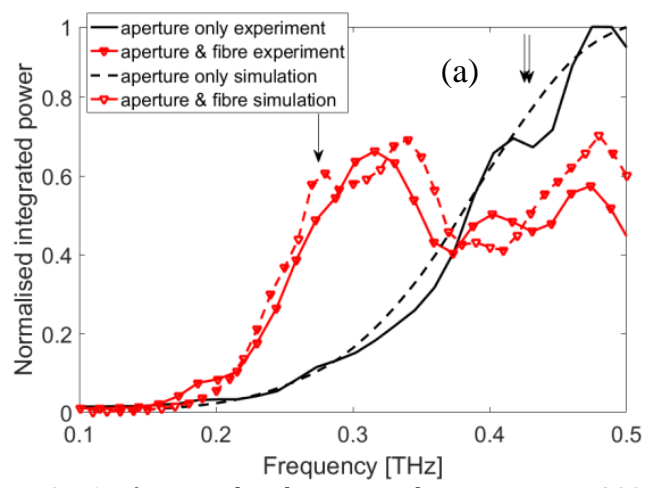

(b)

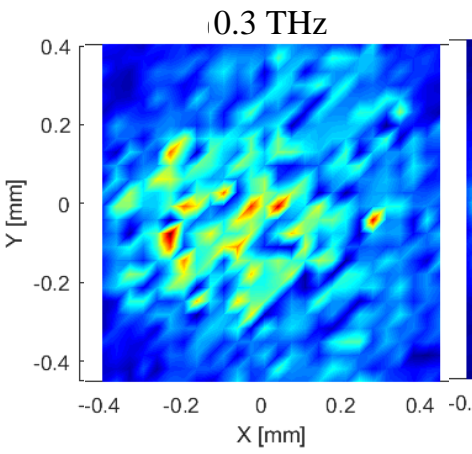

(c) $0.3 \mathrm{THz}$

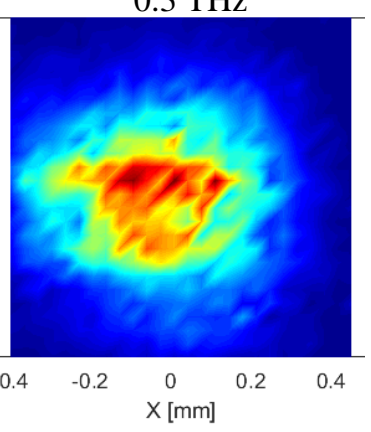

Fig. 1 (a) Normalized integrated power over a 300um diameter aperture (black curves) and aperture-fiber (red curves with triangle markers). The solid and dotted lines represent the experimental and simulated results. Vertical arrows show the position of WGMs. (b) Electric field intensity at $0.3 \mathrm{THz}$ for (b) aperture only and (c) aperture and fiber.

As a first order approximation, a sub-wavelength aperture in a perfect conducting plane can be expressed with effective electric and magnetic dipole moments [3]. Therefore, the enhanced response observed here is due to the presence of both electric and magnetic localized sources. Further studies will analyze the response of the coupled fiber and localized magnetic source [4,5]. Consequently, we will be able to investigate the contribution of the electric and magnetic response within each resonance of this coupled system.

\section{Example References}

[1] S. Atakaramians, A. E. Miroshnichenko, I. V. Shadrivov, A. Mirzaei, Y. S. Kivshar, T. M. Monro, S. Afshar V., "Strong magnetic response of optical nanofibers," ACS Photonics 3, 972-978 (2016).

[2] W. Withayachumnankul et al. "T-ray Sensing and imaging," Proceedings of the IEEE, Special Issue on: T-ray Biosensing and Security, 95, 1528-1558 (2007).

[3] J. D. Jackson, "Classical Electrodinamitcs," $3^{\text {rd }}$. ed., (John Wiley \& Sons, 1998).

[4] S. Afshar V, M. R. Henderson, A. D. Greentree, B. C. Gibson, T. M. Monro, "Self-formed cavity quantum electrodynamics in coupled dipole cylindrical-waveguide systems," Opt. Express 22, 11301-11311 (2014).

[5] S. Afshar V. et al., "Purcell Effect of Magnetic Dipoles in Nanofibers," submitted CLEO/Europe-EQEC 2017. 